\title{
Stigma and Discriminatory Attitude towards People Living with HIV/AIDS among High School Students
}

\author{
Kebebew T
}

Private Consultant, Addis Ababa, Ethiopia

*Corresponding author: Kebebew T, Private Consultant, P.O Box 28533/1000, Addis Ababa, Ethiopia, Tel: + 251911450981,E-mail: tolchakebebew@gmail.com

Citation: Kebebew T (2018) Stigma and Discriminatory Attitude towards People Living with HIV/AIDS among High School Students. J Aids Hiv Infec 4(1): 105. doi: 10.15744/2454-499X.4.105

Received Date: August 7, 2017 Accepted Date: June 28, 2018 Published Date: July 01, 2018

\begin{abstract}
Background: In 1987, the World Health Organization Global Programme on AIDS identified three phases of the HIV/AIDS epidemic: the epidemic of HIV, the epidemic of AIDS, and the epidemic of stigma and discrimination. The report also notified that the third phase is a central issue to the global AIDS challenge and the disease itself. Despite continued multilateral efforts to tackle HIV/AIDS, stigma and discrimination remain among the most poorly understood aspects of the epidemic. In this paper, stigma and discriminatory attitude among high school students was assessed.

Methods: School based cross-sectional study was conducted in two high schools in North Shoa Zone, Oromia Region, Ethiopia. Data was collected by a self-administered structured questionnaire in Afan Oromo, the local language. Socio-demography, HIV test history and stigma and discriminatory attitude of the students were assessed. Description of prevalence of stigma and discriminatory attitude towards people with HIV/AIDS was made using frequencies and mean score. Factors associated with stigma and discriminatory attitude were identified using t-test and one way analysis of variance.

Result: A total sample of 722 was included in the study. Stigma and discriminating attitude was found to be high among high school students: $43 \%$ of the students were not willing to live with people with HIV in the same house; $40 \%$ of them agreed with the statement that said "People with HIV should be isolated"; and 30\% of them believed that people with HIV deserve the suffering because they thought that these people had done something wrong. Educational status, place of residence, marital status, sexual activity and living environment had significant association with stigma and discriminatory attitude.
\end{abstract}

Conclusion: It was found in this study that high proportion of the students expressed stigma and discrimination against people living with HIV. HIV/AIDS education and behavioral change interventions that target the public, especially the youth, are recommended.

Keywords: Attitude; Discrimination; HIV/AIDS; Stigma; Students

List of abbreviations: AIDS: Acquired Immune Deficiency Syndrome; ANOVA: Analysis of Variance; ART: Antiretroviral Therapy; EPHA: Ethiopian Public Health Association; HIV: Human Immunodeficiency Virus; PLWHA: People Living With HIV/AIDS; WHO: World Health Organization

\section{Introduction}

HIV/AIDS is one of the worst epidemics that mankind has faced. AIDS epidemic claimed 3 million lives in 2003. More than 40 million people live with HIV/AIDS worldwide in 2003 [1,2]. Ethiopia is one of the countries with highest prevalence of HIV in the world. About $3.5 \%$ of the population lives with HIV infection, according to the national AIDS Report [3]. National adult HIV prevalence was estimated at 6.6 percent in $2002-13.7$ percent in urban areas and 3.7 percent in rural areas. About 219,400 Ethiopians were estimated to be living with AIDS in 2005. High school students, out of school youths, female sex workers, drivers and uniformed personnel are among most at risk population in Ethiopia $[3,4]$.

Right from the beginning, the epidemic of HIV/AIDS has been accompanied by an epidemic of fear, ignorance, and denial leading to stigmatization of, and discrimination against people living with HIV/AIDS (PLWHA) and their family members [5]. HIV/ 
AIDS-related stigma refers to prejudice, discounting, discrediting, and discrimination directed at people perceived to have AIDS or HIV, and the individuals, groups, and communities with which they are associated [5]. Discrimination can be defined as any action or measure that results in someone being treated less favorably because they have, or are believed to have, HIV. When stigmatization turns into action, it becomes discrimination $[5,6]$. The essence of HIV related discrimination is that it interacts with pre-existing sources of stigma and discrimination against marginalized groups who are discriminated against either on the basis of their known HIV status or on grounds of their assumed HIV status, double discrimination [6,7]. World Health Organization (WHO) Global Program on AIDS has also addressed public health importance of HIV/AIDS related stigma and discrimination. In its report, it has identified three phases of the HIV/AIDS epidemic: the epidemic of HIV, the epidemic of AIDS, and the epidemic of stigma, discrimination $[5,6,8]$.

Stigma and discrimination related to HIV/AIDS are the biggest and most difficult challenges facing health, human rights and HIV/AIDS advocates. Because of stigma in the community, in the workplace, and in health care settings, many people living with HIV/AIDS are afraid to seek treatment, particularly antiretroviral therapy (ART). Stigma also makes it difficult for people to get tested for HIV for fear that they may lose their jobs, or lose respect in the community due to their sero-status. The end result is that people who need testing, treatment, and care will be too afraid to get it, will be forced to get it too late, or will not get it at all, $[6,7,9,10]$.

Socio-demographic characteristics such as age, gender, educational and religious background, HIV related knowledge, personal acquaintance with PLWHA, anti-homosexual attitudes, and perceived responsibility for the HIV infection and sympathy towards PLWHA were associated with discriminatory attitudes towards PLWHA [6,11]. Stigma and discrimination also decrease family's or community's attitude of caring for people with HIV [12].

Many beliefs and facts also contribute to the stigmatization of PLWHA. These include "AIDS is a life-threatening disease"; "AIDS is associated with a degradation of the body including lesions associated with Kaposi Sarcoma and wasting"; "HIV is infectious"; "HIV is associated with heterosexuality, homosexuality and injecting drug use"; "HIV is perceived by the religious and moral beliefs of others to be punishment for a moral fault, such as promiscuous or 'deviant' sex"; and "HIV is associated with minorities already stigmatized and discriminated against - especially the poor". HIV related stigma also builds upon and reinforces existing social stereotypes and inequalities $[6-8,13,14]$.

Recognizing stigma is the first step to combating it. It is quite evident from studies that people with HIV/AIDS are unfairly treated or discriminated against because of their actual or suspected HIV/AIDS status [15,16]. However, there exists little research on how people with HIV/AIDS, or those suspected of having HIV/AIDS, are perceived and treated in Ethiopia.

To stop stigma in the communities, health workers and policy makers must be aware of the level of fear, stigma and discrimination relating to HIV and AIDS. Policy makers need such finding to design target specific programs to combat HIV/AIDS related stigma and discrimination. These interventions may include promoting HIV testing and being openly discussing sero-status; open discussion between colleagues, family members, and friends about AIDS to dispel false myths that cause stigma; openly providing HIV services and disseminate factual HIV information to help change community's attitudes towards HIV; treating every client with fairness, dignity, and the same standard of care; ensuring that client privacy and confidentiality are respected regardless of HIV status; and, researching on how stigma has affected private and social services, [6,17].

In this paper, the author assessed the level of stigmatizing and discriminatory attitudes among high school students. The attitude was measured by three categories of items: the blaming attitude, the avoidant attitude, and attitudes against basic human rights of people with HIV such as having marriage and living with in the general public. Socio-demographic factors were also assessed against such attitudes.

\section{Methods}

School based cross-sectional survey was conducted in June 2006 to describe level of and factors associated with stigma and discriminatory attitude towards people with HIV. The study was conducted in two randomly selected high schools, schools with grade 10-12 students, Muke Turi and Fiche High Schools which are found in North Shoa Zone of Oromia Region, Ethiopia.

A total of 722 complete interviews were made in the study. Study participants were selected from the schools using multistage random sampling techniques. Equal number of study participants was taken from each school. Stratified random sampling technique was used to select sample from grades 10-12 based on total number of students in each grade. Number of sections in each grade was identified and selected using simple random sampling technique. All students in the sections who were available during data collection day were taken.

Data was collected using self-administered and structured questionnaire that has three sections: socio-demography, HIV test history and sexuality, and stigma and discriminatory attitude towards people with HIV. Study tool was adopted from previous 
researches $[6,15,16,18-21]$. Items used in these studies were pooled, reviewed and adopted to the local context. Final items were identified after analyzing consistency during the pretest. The tool was translated to Afan Oromo, the local language.

Data from complete interviews were entered in to database designed in EPI Info and transferred to SPSS for analysis. The attitude measuring items had four responses, 1-Strongly disagree, 2- Disagree, 3-Agree and 4-Strongly Agree with stigmatizing statements. Responses 3 or 4 in this scale were taken as stigma or discriminatory attitude. Half of the items were reversed during data collection and corrected during data management and analysis. Descriptive analyses of socio-demography, HIV test history and sexual activity, and stigma and discriminatory attitude were conducted using frequency, percent and mean scores. Factors associated with the stigma and discrimination were identified by bi-variate analysis using t-test and one way analysis of variance (ANOVA).

Ethical approval and clearance was obtained from Ethical Review Committee of College of Health Sciences, Addis Ababa University. Informed consent form was prepared and attached to the self-administered questionnaire. On the informed consent explained was the purpose of the study. Participants were also assured that data confidentiality and anonymity would be maintained. Permission was also obtained from the schools administrators and teachers.

\section{Result}

\section{Socio-demography of the students}

The age of the study participants ranges from 15 to 28 years (Table 1). Majority, $631(87.6 \%)$ were between the ages 15 and 19 years. Out of the total sample, 504 (69.8\%) were male. Seven hundred eight (98.1\%) were Oromo, while 698 (96.7\%) were Orthodox Christian. On the other hand, 483 (66.9\%) were from rural areas and 550 (76.2\%) live with their parents.

\begin{tabular}{|c|c|}
\hline Variable & N (\%) \\
\hline \multicolumn{2}{|l|}{ Age (years) } \\
\hline $\begin{array}{l}15-19 \\
20-24 \\
25-28\end{array}$ & $\begin{array}{l}633(87.7 \%) \\
83(11.5 \%) \\
6(0.8 \%)\end{array}$ \\
\hline \multicolumn{2}{|l|}{ Sex } \\
\hline $\begin{array}{l}\text { Male } \\
\text { Female }\end{array}$ & $\begin{array}{l}504(69.8 \%) \\
218(30.2 \%)\end{array}$ \\
\hline \multicolumn{2}{|l|}{ Ethnicity } \\
\hline $\begin{array}{l}\text { Oromo } \\
\text { Amhara } \\
\text { Others }\end{array}$ & $\begin{array}{l}708(98.0 \%) \\
11(1.5 \%) \\
3(0.5 \%)\end{array}$ \\
\hline \multicolumn{2}{|l|}{ Religion } \\
\hline $\begin{array}{l}\text { Orthodox } \\
\text { Protestant } \\
\text { Others }\end{array}$ & $\begin{array}{l}698(96.7 \%) \\
16(2.2 \%) \\
8(1.1 \%)\end{array}$ \\
\hline \multicolumn{2}{|l|}{ Residence } \\
\hline $\begin{array}{l}\text { Rural } \\
\text { Urban }\end{array}$ & $\begin{array}{l}483(66.9 \%) \\
239(33.1 \%)\end{array}$ \\
\hline \multicolumn{2}{|l|}{ With whom do live? } \\
\hline $\begin{array}{l}\text { Parents } \\
\text { Relatives } \\
\text { Friends } \\
\text { Others }\end{array}$ & $\begin{array}{l}550(76.2 \%) \\
68(9.4 \%) \\
89(12.3 \%) \\
15(2.1 \%)\end{array}$ \\
\hline
\end{tabular}

Table 1: Socio-demographic characteristics, June 2006

\section{HIV Test and Sexual Activity}

One hundred eighty-six (25.8\%) of the study participants were tested for HIV (Table 2). About 95\% of the students were single whereas $2.5 \%$ were married. Five hundred eighty-five $(81 \%)$ of the students claimed that they had no sexual activity, while 84 (11.6\%) said they ever had sexual intercourse only with one sexual partner. Fifty three (7.3\%) subjects reported that they had sexual intercourse with more than one partner. 


\begin{tabular}{|l|l|}
\hline Items & $\mathbf{N}(\mathbf{\%})$ \\
\hline Ever Test for HIV & \\
\hline Yes & $\mathbf{1 8 6}(\mathbf{2 5 . 8 \% )}$ \\
\hline No & $\mathbf{5 3 6}(\mathbf{7 4 . 2 \%})$ \\
\hline Marital Status & \\
\hline Single & $\mathbf{6 9 6}(\mathbf{9 6 . 4 \% )}$ \\
\hline Married & $\mathbf{1 8}(\mathbf{2 . 5 \% )}$ \\
\hline Separated & $\mathbf{5 ( 0 . 7 \% )}$ \\
\hline Divorced & $\mathbf{3 ( 0 . 4 \% )}$ \\
\hline $\begin{array}{l}\text { Number of sex } \\
\text { partners }\end{array}$ & $\mathbf{5 8 5 ( 8 1 . 0 \% )}$ \\
\hline None & $\mathbf{8 4}(\mathbf{1 1 . 6 \% )}$ \\
\hline One & $\mathbf{5 3 ( 7 . 3 \% )}$ \\
\hline More than one
\end{tabular}

Table 2: HIV test history and sexual activity, June 2006

\section{Stigma and Discriminatory Attitudes}

Large number of study participants had discriminatory attitude towards people with HIV/AIDS. All participants had agreed or strongly agreed with at least one of the items used for measuring stigma and discrimination. The mean and standard deviation score of stigma and discriminatory attitude towards PLWHA, scored out of four, was $1.88+0.53$. One hundred thirty (18.0\%) had average score greater than 2.50 , which means that they had discriminatory attitude by an aggregate item (Table 3 ).

\begin{tabular}{|l|l|l|}
\hline \multicolumn{2}{|l|}{ Stigma and Discriminatory Attitude Items } & N (\%) \\
\hline \multicolumn{2}{|l|}{ Blaming Attitudes } & \\
\hline $\mathbf{1}$ & People who have AIDS cannot be trusted & $204(28.3 \%)$ \\
\hline $\mathbf{2}$ & Most people become HIV positive by being weak or foolish & $140(19.4 \%)$ \\
\hline $\mathbf{3}$ & People who have AIDS are cursed & $91(12.6 \%)$ \\
\hline $\mathbf{4}$ & $\begin{array}{l}\text { A person with AIDS must have done something wrong and deserves to } \\
\text { be punished }\end{array}$ & $221(30.6 \%)$ \\
\hline & Aggregate score above mid-point & $178(24.7 \%)$ \\
\hline Avoidant Attitudes & Living with someone who has HIV/AIDS causes a problem. & $311(43.1 \%)$ \\
\hline $\mathbf{5}$ & It is not safe for a student to be taught by HIV positive teachers at school & $91(12.6 \%)$ \\
\hline $\mathbf{6}$ & One should not share a meal with a person who is positive for HIV/AIDS & $75(10.4 \%)$ \\
\hline $\mathbf{7}$ & $\begin{array}{l}\text { One should not buy food items from a shopkeeper or food seller who is } \\
\text { known to have HIV/AIDS }\end{array}$ & $135(18.7 \%)$ \\
\hline $\mathbf{8}$ & Aggregate score above mid-point & $158(21.9 \%)$ \\
\hline $\mathbf{9}$ & People with HIV should not get married & $271(37.5 \%)$ \\
\hline $\mathbf{A}$ & Aggregate score above mid-point & $289(40.0 \%)$ \\
\hline $\mathbf{1 0}$ & Pverall aggregate score above mid-point & $130(18.0 \%)$ \\
\hline
\end{tabular}

Table 3: Stigma and discriminatory attitude among high school students, June 2006

The average score of items of the category blaming attitude, computed from four items, was $1.79+0.60$; and, 178 (24.7\%) of the subjects agreed with all items used to measure the blaming attitudes. On the other hand, the average score of the avoidant attitudes was $1.78 \pm 0.62$, and 158 (21.9\%) subjects agreed with all avoidant attitudes. Similarly, the average score of negative attitude towards the right of PLWHA was high, $2.25 \pm 0.98$, and, 400 (55.4\%) of the subjects had negative attitude towards the rights of PLWHA.

The highest discriminatory attitude was observed among items under category of avoidant attitudes. For example, 311 (43.1\%) subjects were not willing to live with people with HIV in the same house. High proportion (40.0\%) did also agree with the statement that says "People who have HIV should be isolated". Comparable proportion also said that people with HIV should not get married. Similarly, $30.6 \%$ of the study participants agreed with the statement "A person with AIDS must have done something wrong and deserves to be punished" (Table 3). 


\section{Factors Associated with Attitude against PLWHA}

The aggregate attitude score was used in comparing the stigma and discriminatory attitude among some socio-demographic variables using independent sample t-test and one way ANOVA. Only bivariate analysis was conducted because the independent factors list was not supposed to be exclusive. Stigma and discriminatory attitude showed statistically significant variation by school, educational status, place of residence, marital status and living condition, $\mathrm{p}<0.05$ (Table 4).

\begin{tabular}{|c|c|c|c|c|}
\hline Variables & Categories & Above Mid-Point (\%) & Mean Score $/ 4.00$ & p-value (2 tailed) \\
\hline \multirow{2}{*}{ School } & Muke Turi & 19.4 & 1.92 & \multirow{2}{*}{$0.03^{*}$} \\
\hline & Fiche & 16.6 & 1.84 & \\
\hline \multirow{3}{*}{ Grade } & 10 & 21.1 & 1.96 & \multirow{3}{*}{$0.00^{* *}$} \\
\hline & 11 & 9.3 & 1.70 & \\
\hline & 12 & 12.9 & 1.69 & \\
\hline \multirow{3}{*}{ Age (Years) } & $15-19$ & 17.8 & 1.89 & \multirow{3}{*}{0.53} \\
\hline & $20-24$ & 21.7 & 1.82 & \\
\hline & $25-28$ & 0.0 & 1.93 & \\
\hline \multirow{2}{*}{ Sex } & Male & 18.1 & 1.86 & \multirow{2}{*}{0.08} \\
\hline & Female & 17.9 & 1.93 & \\
\hline \multirow{2}{*}{ Residence } & Rural & 20.9 & 1.94 & \multirow{2}{*}{$0.00^{* *}$} \\
\hline & Urban & 12.1 & 1.76 & \\
\hline \multirow{2}{*}{ HIV Test } & Yes & 15.6 & 1.86 & \multirow{2}{*}{0.49} \\
\hline & No & 18.8 & 1.89 & \\
\hline \multirow{3}{*}{ Number of sexual partner } & None & 16.8 & 1.85 & \multirow{3}{*}{$0.01^{*}$} \\
\hline & One & 26.2 & 1.97 & \\
\hline & Two or More & 18.9 & 2.05 & \\
\hline \multirow{4}{*}{ Marital Status } & Single & 17.2 & 1.87 & \multirow{4}{*}{$0.03^{*}$} \\
\hline & Married & 38.9 & 2.16 & \\
\hline & Separated & 40.0 & 2.18 & \\
\hline & Divorced & 33.3 & 2.33 & \\
\hline \multirow{2}{*}{ Ethnicity } & Oromo & 18.1 & 1.88 & \multirow{2}{*}{0.22} \\
\hline & Amhara & 9.1 & 1.67 & \\
\hline \multirow{2}{*}{ Religion } & Orthodox & 17.8 & 1.88 & \multirow{2}{*}{0.11} \\
\hline & Protestant & 12.5 & 1.67 & \\
\hline \multirow{4}{*}{ Living Environment } & With Parents & 18.6 & 1.89 & \multirow{4}{*}{$0.04^{*}$} \\
\hline & With Relatives & 16.2 & 1.84 & \\
\hline & With Friends & 18.0 & 1.93 & \\
\hline & Others & 6.7 & 1.46 & \\
\hline
\end{tabular}

${ }^{*}$ Statistically significant difference at $0.05 ;{ }^{*}$ Statistically Different at 0.01

Table 4: Covariates of stigma and discriminatory attitudes, June 2006

Students at Muke Turi High School showed higher level of stigma and discrimination: 19.4\% expressed stigmatizing attitude, in average, as compared to $16.6 \%$ of students at Fiche High School, $\mathrm{p}<0.05$. There was inverse relationship between educational status, measured by grade completed, and the discriminatory attitude. Higher proportion of grade 10 students (21.1\%) showed discriminatory attitude when compared to those in grade 11 and 12 (9.3\% and $12.9 \%), \mathrm{p}<0.01$ (Table 4).

Students from rural areas showed higher level of stigma and discrimination. In average, $20.9 \%$ of the students from rural areas and $12.1 \%$ of those from urban areas expressed stigmatizing and discriminatory attitude which is statistically significant, $\mathrm{p}<0.01$. Sexual activity and marital status were also the factors that were significantly associated with the attitude. Students with no sexual partner and who were single had less stigma and discrimination attitude as compared to those who had one or more sexual partner and those with marriage relationship, $\mathrm{p}<0.05$. Students who lived with parents and friends showed higher stigma and discriminatory attitude when compared to those who lived independently or lived with relatives, $\mathrm{p}<0.05$ (Table 4 ).

\section{Discussion}

Stigma related to HIV/AIDS is reported as early as the emergence of HIV. It fuels transmission of the virus in different ways. In the community with stigma against PLWHA, people are not willing to know their sero-status as they fear to disclose it. This will 
prevent behavioral change and also decrease their intention to prevent infecting others. Stigma also prevents caring for PLWHA. It also prevent PLWHA from accessing HIV/AIDS treatment, care and support services.

In this study, stigma and discriminatory attitude of high school students was assessed. The finding indicated that all students expressed some king of stigma or discriminatory attitude. Avoidant behavior was found to be the highest: $43 \%$ of the respondents were not willing to live with HIV positive people in the same house. One in five students was also not willing to buy food items from an HIV positive shopkeeper. Although a comprehensive HIV knowledge was not assessed in this study, such avoidant behavior could be related to low HIV transmission knowledge. Many studies showed similar findings. A study conducted in India showed that about 50\% of Indians had avoidant behavior against PLWHA [22]. In Nigeria, $64.5 \%$ of university students were not willing to live with HIV positive students [23]. The avoidant behavior was found to be higher among students as compared to the general population in these studies.. However, there are also communities with more stigmas among general population than among students. A higher proportion of Botswana population (60\%) expressed refusal to buy food items from HIV positive shopkeeper [19]. In the same study, $42 \%$ of the population was not willing to send their students to schools to be taught by HIV positive teacher which is higher than the finding of this study.

In this study, forty percent of the study participants wanted HIV positive people are isolated. Studies in China and South Africa showed similar findings $[21,24,25]$. Even more proportion of population, more than $80 \%$, had such attitude in Botswana and India $[19,20,22]$.

Blaming attitude was also found high in this study. About $30 \%$ of students participated in this study showed an attitude that HIV positive people deserve the punishment because they thought that these people had done something wrong. This result is higher than figures report from China, which was 14\%; however, it was comparable with the result of a study in India, which was $30 \%$ $[20,24]$. Other type of blaming attitude was also reported in this study. About one in five students support the attitude expressed as "People who have HIV/AIDS are cursed, foolish or they cannot be trusted". Blaming attitude is known to be associated with underlying low HIV/AIDS knowledge, fear, sexual norms and cultures [2,9,11,19,21,24,25].

\section{Conclusion}

This study documented the widespread stigma and discrimination towards PLWHA. Significantly higher proportion of high school students expressed blaming, isolating and avoidant attitude towards PLWHA. Therefore, there is an urgent need to educated youths, especially students. They need to know that HIV/AIDS cannot be contracted through some ridiculous means like living together in a house, handshakes, sharing of utensils and toilet facilities. The government, the civil society and all stakeholders should carry out massive publicity in the schools to create understanding of the disease and support PLWHA.

\section{Acknowledgement}

I would like to thank administrators of Fiche and Muke Turi High Schools, teachers and the students for their willingness to take part in this study. My gratitude also goes to School of Public Health, Addis Ababa University for its facilitation for ethical approval and technical support. My acknowledgement also goes to the Ethiopian Public Health Association (EPHA) for sponsoring the research project.

\section{References}

1. WHO, The World health report: 2004: changing history. 2004, World Health Organization.

2. Nyblade L, Pande R, Mathur S, MacQuarrie K, Kidd R,et al. (2003) Disentangling HIV and AIDS STIGMA in Ethiopia, Tanzania and Zambia. International Center for Research on Women (ICRW).

3. MOH (2005) AIDS in Ethiopia: Sixth Report. Federal Ministry of Health/ National HIV/AIDS Prevention and Control Office.

4. HIV/AIDS, JUNPo, WH Organization (2007) AIDS epidemic update, December 2006. World Health Organization.

5. Klein SJ, Karchner WD, O’Connell DA (2002) Interventions to prevent HIV-related stigma and discrimination: findings and recommendations for public health practice. J Public Health Manag Pract 8: 44-53.

6. Parker R, Aggleton P (2003) HIV/AIDS-related Stigma and Discrimination: A Conceptual Framework and an Agenda for Action. Soc Sci Med 57:13-24.

7. Aggleton P (2002) Barcelona 2002: law, ethics, and human rights. HIV/AIDS-related stigma and discrimination: a conceptual framework. Can HIV AIDS Policy Law Rev 7: 115-6.

8. de Bruyn T (2002) HIV-related stigma and discrimination--the epidemic continues. Can HIV AIDS Policy Law Rev 7: 8-14.

9. Kiflie Y (2001) Social Stigma Attached to HIV/AIDS and Its Determinants in Dire Dawa Town. School of Public Health, Addis Ababa University: Addis Ababa. 10. Mawar N, Saha S, Pandit A, Mahajan U (2005) The third phase of HIV pandemic: Social consequences of HIV/AIDS stigma \& discrimination \& future needs. Indian J Med Res 122: 471-84.

11. Guma M, Henda N, Petros G (2003) Disparities in attitudes towards People Living with HIV/AIDS (PLWA): A Nationwide Study. Human Sciences Research Council: Cape Town, South Africa.

12. Green DA, Devi S, Paulraj LS (2007) Care centre visits to married people living with HIV: an indicator for measuring AIDS-related stigma \& discrimination. AIDS Care 19: 910-5.

13. Parker R, Aggleton P (2003) HIV/AIDS-related Stigma and Discrimination: A Conceptual Framework and an Agenda for Action. Soc Sci Med 57:13-24. 
14. Omoteso BA (2004) Perception of HIV/AIDS as correlate of attitude towards HIV infected students among university undergraduate students in southwestern Nigeria. in African Symposium 4: 5.

15. Letamo G (2004) HIV/AIDS-Related Stigma and Discrimination among Adolescents in Botswana. Afr Popul Stud 19: 191-204.

16. Skinner D, Mfecane S (2004) Stigma, discrimination and the implications for people living with HIV/AIDS in South Africa. SAHARA J 1: 157-64.

17. Betteridge G (2005) Legal Network launches Plan of Action on HIV/AIDS-related stigma and discrimination. HIV AIDS Policy Law Rev 10: $32-4$.

18. Herek GM, Capitanio JP, Widaman KF (2002) HIV-related stigma and knowledge in the United States: prevalence and trends, 1991-1999. Am J Public Health 92: $371-7$.

19. Letamo G (2003) Prevalence of, and Factors Associated with, HIV/AIDS-related Stigma and Discriminatory Attitudes in Botswana. J Health Popul Nutr 21: 347-57.

20. Pramanik S, Chartier M, Koopman C (2006) HIV/AIDS stigma and knowledge among predominantly middle-class high school students in New Delhi, India. J Commun Dis 38: 57-69.

21. Simbayi LC, Kalichman S, Strebel A, Cloete A, Henda N, et al. (2007) Internalized stigma, discrimination, and depression among men and women living with HIV/AIDS in Cape Town, South Africa. Soc Sci Med 64: 1823-31.

22. Sudha RT, Vijay DT, Lakshmi V (2005) Awareness, attitudes, and beliefs of the general public towards HIV/AIDS in Hyderabad, a capital city from South India. Indian J Med Sci 59: 307.

23. Adepeju, B., Perception Of HIV/AIDS as Correlate of Attitude Towards HIV Infected Students Among University Undergraduate Students in Southwestern Nigeria. African Educational Research Network, 2004. 4(2).

24. Lau JTF, Tsui HY (2005) Discriminatory attitudes towards people living with HIV/AIDS and associated factors: a population based study in the Chinese general population. Sex Transm Infect 81: 113-9.

25. Cao X, Sullivan SG, Xu J, Wu Z, China CIPRA Project 2 Team (2006) Understanding HIV-related stigma and discrimination in a "blameless" population. AIDS Educ Prev 18: 518-28. 